\title{
Bone geometry and volumetric bone mineral density in girls with Turner syndrome of different pubertal stages
}

\author{
Ondrej Soucek*, Jan Lebl*, Marta Snajderova*, Stanislava Kolouskova*, Miloslav Rocek†, Zdenek Hlavkał, \\ Ondrej Cinek*, Joern Rittweger§'ণ and Zdenek Sumnik*
}

${ }^{*}$ Department of Pediatrics, $\dagger$ Department of Radiological Techniques, University Hospital Motol, 2nd Faculty of Medicine, $\ddagger$ Department of Probability and Mathematical Statistics, Faculty of Mathematics and Physics, Charles University, Prague, Czech Republic, \$Institute of Aerospace Medicine, German Aerospace Center (DLR), Cologne, Germany and Institute for Biomedical Research into Human Movement and Health, Manchester Metropolitan University, Manchester, UK

\section{Summary}

Objective An increased rate of fractures has been reported in patients with Turner syndrome (TS). We aimed to assess bone geometry and volumetric bone mineral density (vBMD) at the radius in girls with TS and to evaluate the relationships between bone parameters and fracture history.

Methods and design Sixty-seven girls with TS aged 6-19 years treated currently or in the past with growth hormone $(\mathrm{GH})$ and/or oestrogens were examined using peripheral quantitative computed tomography. Results were compared to reference data.

Results Cortical area and cortical thickness were low in all age groups (all $P<0.001$ ). Height-adjusted total bone area at the diaphysis was increased in prepubertal and postpubertal girls (mean $Z$-score 1.0, $P<0.05$ for both) and normal in the pubertal group (mean $Z$-score $0 \cdot 1$ ). Cortical vBMD was decreased (mean age-specific $Z$-scores $-2 \cdot 0,-1 \cdot 6$ and $-1 \cdot 0$ for prepubertal, pubertal and postpubertal groups, respectively, $P<0.01$ for all groups). Height- , age- and cortical thickness-adjusted cortical vBMD was positively correlated to the duration of GH therapy $(P=0 \cdot 012)$ and to oestrogen administration $(P=0 \cdot 047)$. Girls with a history of fractures had lower total vBMD at the metaphysis compared to nonfractured TS girls (mean $Z$-scores $-1.7 v s-0.9, P=0.04$ ).

Conclusions There is a cortical bone deficit in girls with TS characterized by low cortical area, thin cortex and probably decreased cortical vBMD. Early commencement of GH therapy, as well as oestrogen replacement, is associated with higher cortical vBMD. Further studies should investigate the potential causality of this relation.

(Received 3 September 2010; returned for revision 15 October 2010; finally revised 2 December 2010; accepted 3 December 2010)

Correspondence: Ondrej Soucek, Department of Pediatrics, University Hospital Motol, V Uvalu 84, 15006 Prague, Czech Republic.

Tel.: +420 22443 2090; Fax: +420 22443 2020;

E-mail: ondrej.soucek@lfmotol.cuni.cz

\section{Introduction}

A significant increase in fracture rate has been described in females with Turner syndrome compared to the general population. ${ }^{1,2}$ The aetiology of increased bone fragility in Turner syndrome (TS) has not yet been completely elucidated. Traditionally, it is attributed to oestrogen insufficiency because of hypogonadism and/or to a primary bone defect linked to sex chromosome haploinsufficiency.

Several studies using dual-energy x-ray absorptiometry (DXA) have reported decreased bone mineral density (BMD) in females with TS, in whom a variable decrease in lumbar spine BMD was observed with mean $Z$-scores ranging from $-2 \cdot 3$ to $-0 \cdot 8 .^{3-5}$ However, planar methods - such as X-ray absorptiometry - are inherently limited in that they ignore the third bone dimension. People with a short stature, such as patients with TS, are assigned artificially decreased areal bone mineral density (aBMD) on planar methods. ${ }^{6}$ Indeed, substantially better lumbar spine BMD values are obtained when appropriate adjustments are made for body height or bone size. By increasing the mean $Z$-scores by $0 \cdot 3-1 \cdot 8$, such a size adjustment led to a significant reduction in the number of TS patients diagnosed with osteoporosis. $^{3-5}$ Compared to planar densitometry, quantitative volumetric techniques such as the peripheral quantitative computed tomography (pQCT) have several advantages for the study of bone: they are not affected by bone size, they distinguish trabecular from cortical volumetric BMD (vBMD), and they assess bone geometry. Along with low radiation dose, pQCT is thus a useful tool for analyses of bone properties in short and disproportional children.

To our best knowledge, only three studies have applied volumetric techniques on patients with TS, all performed on patient groups of a rather limited size. Nanao et al. reported decreased lumbar spine vBMD in 21 girls with TS using QCT. ${ }^{7}$ Bechtold et al. ${ }^{8}$ reported decreased total vBMD in 21 young adults with TS using pQCT at the radius, and Holroyd et al. ${ }^{9}$ found decreased cortical vBMD, but normal trabecular vBMD in 22 TS girls by the same method. Given the small sample sizes in the former studies, the lack 
of knowledge regarding the effect of growth hormone (GH) and oestrogens on bone variables, and still missing data regarding the indicators of bone strength, we set out to elucidate this topic in a larger sample of patients with TS. Moreover, we report for the first time height-specific $Z$-scores for volumetric bone parameters in TS.

The aims of our study were as follows: (i) to assess bone geometry and volumetric BMD at the radius in girls with TS comparing the parameters between prepubertal, pubertal and postpubertal groups; (ii) to investigate the impact of the duration of growth hormone therapy and oestrogen replacement on their bone; and (iii) to compare densitometric indicators of bone strength between girls with history of fractures and nonfractured girls.

\section{Patients and methods}

\section{Subjects}

We examined 67 girls with TS aged 6-19.4 years, selected from 82 girls with TS that were regularly followed up at the University Hospital Motol in Prague, Czech Republic. The reasons for excluding the remaining 15/82 girls were as follows: coeliac disease (5), inflammatory bowel disease (2), poor cooperation during densitometry (3) and patient refusal (5). Using Tanner's classification of puberty, all girls presenting with breast stage 1 were considered prepubertal, the girls with breast stage 2 or more were considered pubertal. The end of the puberty was defined by cessation of body growth, i.e. by the time GH therapy has been stopped for at least 6 month. All postpubertal girls had breast Tanner stage 4 or 5 . At the time of densitometric testing, 22 girls were prepubertal, 25 girls were pubertal, and 20 girls were postpubertal (Table 1). Their karyotypes were either 45,X (24/67, 36\%), various forms of mosaicism $(35 / 67,52 \%)$ or a structurally abnormal X chromosome $(8 / 67$, $12 \%)$.

The study was approved by the Ethics Committee of the University Hospital Motol, Prague. Informed consent was obtained from all participants and/or their guardians.

\section{Hormone therapy}

At the time of bone densitometry, all prepubertal and pubertal patients with TS were treated with recombinant human GH while postpubertal girls had been off the therapy for a median 1.5 years (range $0 \cdot 6-3 \cdot 7$ ). GH starting dose of $50 \mu \mathrm{g} / \mathrm{kg} /$ day was adjusted during therapy according to clinical response. ${ }^{10}$ Median age at start of GH therapy was $7 \cdot 0$ years (range $2 \cdot 4-15 \cdot 4$ ), median duration of GH administration was $5 \cdot 8$ years (range $0 \cdot 0-11 \cdot 9$ ).

Oestrogen replacement was given to $20 / 25$ patients from the pubertal group and to $19 / 20$ patients from the postpubertal group. The remaining 5/25 pubertal patients entered puberty spontaneously and $1 / 20$ postpubertal patient underwent spontaneous puberty. Oestrogen replacement was started at the median age of $12 \cdot 8$ years (range $10 \cdot 4-16 \cdot 3$ ), with a starting dose of $5 \mu \mathrm{g} / \mathrm{kg} / \mathrm{day}$ of 17- $\beta$-estradiol given for $12-18$ months. ${ }^{11,12}$ Afterwards, a dose of $10 \mu \mathrm{g} / \mathrm{kg} /$ day was administered for another 12-18 months, followed by an increase to $20 \mu \mathrm{g} / \mathrm{kg} /$ day. After a mean period of 3 months, the same dose of estradiol was continued from day 1 to 21 , with $5 \mathrm{mg}$ of medroxyprogesterone per day added from day 15 to 21 . No other medication known to influence bone metabolism was given except for thyroxine substitution for autoimmune thyroiditis in 15 girls, which had been long-term euthyroid before the densitometry.

\section{Measurement methods}

On the day of bone densitometry, body height was measured by stadiometer to nearest $1 \mathrm{~mm}$ and weight was measured by electronic scale to nearest $100 \mathrm{~g}$. Height, weight and BMI $Z$-scores were calculated using national reference data. ${ }^{13}$

Peripheral quantitative CT (XCT 2000; Stratec Medizintechnik, Pforzheim, Germany) was used for bone assessment at the nondominant radius. A single tomographic $2 \mathrm{~mm}$-thick slice was taken at the distance corresponding to $4 \%$ and $65 \%$ forearm length measured from processus styloideus ulnae to the olecranon. Image processing and the calculation of numerical values were carried out using the integrated хст software version 6.00 B. At the distal

Table 1. Clinical characteristics of the study group at the time of peripheral quantitative computed tomography measurement

\begin{tabular}{|c|c|c|c|c|}
\hline & $\begin{array}{l}\text { Prepubertal girls } \\
(N=22)\end{array}$ & $\begin{array}{l}\text { Pubertal girls } \\
(N=25)\end{array}$ & $\begin{array}{l}\text { Postpubertal girls } \\
(N=20)\end{array}$ & $\begin{array}{l}\text { Group difference } \\
(P \text {-value })\end{array}$ \\
\hline Age (year) & $10 \cdot 3(2 \cdot 2)$ & $14 \cdot 3(1 \cdot 7)$ & $17 \cdot 4(1 \cdot 2)$ & $<0 \cdot 001$ \\
\hline Height $(\mathrm{cm})$ & $132 \cdot 8(12 \cdot 9)$ & $149 \cdot 8(6 \cdot 0)$ & $157 \cdot 5(2 \cdot 9)$ & $<0 \cdot 001$ \\
\hline Height $Z$-score & $-1 \cdot 6(1 \cdot 0)^{\star * \star}$ & $-2 \cdot 0(0 \cdot 6)^{\star \star \star}$ & $-1.5(0.5)^{\star * *}$ & $0 \cdot 107$ \\
\hline Weight (kg) & $33 \cdot 3(10 \cdot 4)$ & $47 \cdot 3(7 \cdot 9)$ & $61 \cdot 4(9 \cdot 2)$ & $<0 \cdot 001$ \\
\hline Weight $Z$-score & $-0 \cdot 5(1 \cdot 0)^{*}$ & $-0 \cdot 6(0 \cdot 9)^{* *}$ & $0 \cdot 3(1 \cdot 2)$ & $0 \cdot 009$ \\
\hline $\operatorname{BMI}\left(\mathrm{kg} / \mathrm{m}^{2}\right)$ & $18 \cdot 4(3 \cdot 0)$ & $21 \cdot 0(2 \cdot 7)$ & $24 \cdot 8(3 \cdot 6)$ & $<0.001$ \\
\hline BMI $Z$-score & $0 \cdot 4(0 \cdot 9)^{*}$ & $0.5(0 \cdot 9)^{*}$ & $1 \cdot 1(1 \cdot 0)^{* * *}$ & 0.034 \\
\hline Duration of growth hormone therapy (year) & $4 \cdot 2(3 \cdot 2)$ & $5 \cdot 8(3 \cdot 3)$ & $7 \cdot 7(2 \cdot 1)$ & $0 \cdot 001$ \\
\hline Duration of oestrogen therapy (year) & NA & $1 \cdot 6(0 \cdot 7)$ & $4 \cdot 2(1 \cdot 2)$ & $<0 \cdot 001$ \\
\hline Spontaneous puberty (number of patients) & NA & 5 & 1 & NA \\
\hline
\end{tabular}

Mean (SD) values are shown. Comparison to healthy population was tested by one-sample t-test, sign test was used instead, whenever normality was rejected by Shapiro-Wilk test: ${ }^{\star} P<0 \cdot 05,{ }^{* *} P<0 \cdot 01,{ }^{* *} P<0 \cdot 001$. One-way ANOva was used to compare between the three groups, $P$-value shows the intergroup significances. 
radius ( $4 \%$ site), bone mineral content (BMC), total and trabecular vBMD, total bone cross-sectional area (total area) and polar strength-strain index (SSI) were assessed. Strength/weight index was calculated as proposed by Rauch et al. ${ }^{14}$ At the proximal radius (65\% site), BMC, total and cortical vBMD, total area, cortical cross-sectional area (cortical area), polar SSI and muscle area (MA) were assessed. SSI was determined by using a segmentation threshold of $480 \mathrm{mg} / \mathrm{cm}^{3}$. Total area and cortical area were determined by detecting the outer and inner cortical bone contour at a threshold of $710 \mathrm{mg} / \mathrm{cm}^{3}$. Relative cortical area was mathematically derived by dividing cortical area by total area. Cortical thickness was computed by integrated software under the assumption of a circular ring model. BMC divided by muscle area (BMC/MA ratio) was used to evaluate the muscle-bone unit. $Z$-scores were calculated using published reference data created on the related neighbouring German population ${ }^{15-17}$ using Cole's formula ${ }^{18}$ : $Z$-score $=[\operatorname{Ln}($ patient's test result/M) $] / S$, where $\mathrm{Ln}$ is the natural logarithm, $\mathrm{M}$ corresponds to the age- and sex-specific mean value and $S$ is the age- and sex-specific coefficient of variation. For diaphyseal BMC, total area, cortical area, SSI and muscle area, height-specific $Z$-scores were also calculated using the same literature.
According to the recommendation of the International Society for Clinical Densitometry, ${ }^{19}$ the precision error (expressed as root mean square standard deviation, RMS SD) was calculated from three consecutive measurements with repositioning in fifteen healthy young adult volunteers (mean age $25 \cdot 1$ ). Precision errors of the primary measures were as follows: at the distal radius, BMC $0.943 \mathrm{mg} / \mathrm{mm}$, trabecular vBMD $2.905 \mathrm{mg} / \mathrm{cm}^{3}$, total $\mathrm{vBMD}$ $9.353 \mathrm{mg} / \mathrm{cm}^{3}$, total area $9.617 \mathrm{~mm}^{2}$ and SSI $10.031 \mathrm{~mm}^{3}$; at the proximal radius, BMC $0.745 \mathrm{mg} / \mathrm{mm}$, total vBMD $4.947 \mathrm{mg} / \mathrm{cm}^{3}$, cortical vBMD $4.641 \mathrm{mg} / \mathrm{mm}^{3}$, total area $1.193 \mathrm{~mm}^{2}$, cortical area $1.021 \mathrm{~mm}^{2}$, cortical thickness $0.068 \mathrm{~mm}$, SSI $7.685 \mathrm{~mm}^{3}$ and muscle area $46 \cdot 313 \mathrm{~mm}^{2}$.

\section{Statistical analysis}

All analyses were performed in the statistical computing environment R. ${ }^{20}$ Comparisons with the healthy population were based on the one-sample t-test or the sign test (Tables 1 and $2)$. The one-sample $t$-test was used whenever normality was suggested by the Shapiro-Wilk test. One-way ANOva was used to compare anthropometric and densitometric parameters between prepubertal, pubertal and postpubertal TS girls (Table 2).

Table 2. Bone parameters shown separately for prepubertal, pubertal and postpubertal Turner syndrome girls

\begin{tabular}{|c|c|c|c|c|c|c|c|}
\hline & Value & $Z$-score & Value & $Z$-score & Value & $Z$-score & $\begin{array}{l}\text { Group } \\
\text { difference } \\
(P \text {-value })\end{array}$ \\
\hline \multicolumn{8}{|l|}{ Distal radius } \\
\hline $\mathrm{BMC}(\mathrm{mg} / \mathrm{mm})$ & $59 \cdot 1(15 \cdot 7)$ & $-0 \cdot 5(1 \cdot 2)$ & $74 \cdot 0(13 \cdot 8)$ & $-1 \cdot 2(1 \cdot 3)^{\star * *}$ & $96 \cdot 2(12 \cdot 8)$ & $-0 \cdot 6(0 \cdot 9)^{*}$ & $0 \cdot 070$ \\
\hline Total vBMD $\left(\mathrm{mg} / \mathrm{cm}^{3}\right)$ & $270 \cdot 5(34 \cdot 6)$ & $-0 \cdot 5(1 \cdot 1)^{*}$ & $262 \cdot 5(45 \cdot 0)$ & $-1.4(1.5)^{\star * *}$ & $295 \cdot 0(44 \cdot 7)$ & $-1 \cdot 3(1 \cdot 0)^{\star * *}$ & $0 \cdot 032$ \\
\hline $\operatorname{SSI}\left(\mathrm{mm}^{3}\right)$ & $128 \cdot 9(43 \cdot 0)$ & - & $183 \cdot 0(64 \cdot 3)$ & - & $302 \cdot 0(65 \cdot 2)$ & - & $<0 \cdot 001$ \\
\hline Strength/weight index $\left(\mathrm{mm}^{3} / \mathrm{kg} / \mathrm{m}\right)$ & $21 \cdot 5(6 \cdot 0)$ & - & $18 \cdot 0(6 \cdot 1)$ & - & $22 \cdot 2(6 \cdot 0)$ & - & $0 \cdot 047$ \\
\hline \multicolumn{8}{|l|}{ Proximal radius } \\
\hline $\mathrm{BMC}(\mathrm{mg} / \mathrm{mm})$ & $54 \cdot 1(10 \cdot 8)$ & $-1 \cdot 2(1 \cdot 0)^{\star * *}$ & $69 \cdot 1(10 \cdot 8)$ & $-1 \cdot 5(1 \cdot 2)^{\star * *}$ & $83 \cdot 6(14 \cdot 6)$ & $-1 \cdot 0(1 \cdot 2)^{* *}$ & $0 \cdot 239$ \\
\hline BMC (height adjusted) & & $-0 \cdot 0(1 \cdot 5)$ & & $-0 \cdot 3(1 \cdot 2)$ & & $-0 \cdot 1(1 \cdot 1)$ & $0 \cdot 714$ \\
\hline Total vBMD $\left(\mathrm{mg} / \mathrm{cm}^{3}\right)$ & $510 \cdot 8(100 \cdot 4)$ & $-1 \cdot 5(1 \cdot 6)^{* * *}$ & $652 \cdot 9(99 \cdot 0)$ & $-0 \cdot 6(1 \cdot 1)^{*}$ & $656 \cdot 8(106 \cdot 0)$ & $-1 \cdot 0(1 \cdot 5)^{\star *}$ & $0 \cdot 098$ \\
\hline Cortical area $\left(\mathrm{mm}^{2}\right)$ & $38 \cdot 2(10 \cdot 8)$ & $-1 \cdot 3(1 \cdot 3)^{\star * *}$ & $53 \cdot 4(9 \cdot 3)$ & $-1 \cdot 4(1 \cdot 1)^{\star * *}$ & $62 \cdot 3(11 \cdot 1)$ & $-1 \cdot 2(1 \cdot 2)^{\star * \star}$ & $0 \cdot 867$ \\
\hline Cortical area (height adjusted) & & $-0 \cdot 1(1 \cdot 2)$ & & $-0 \cdot 1(0 \cdot 9)$ & & $0 \cdot 1(0 \cdot 9)$ & $0 \cdot 681$ \\
\hline Relative cortical area & $0 \cdot 43(0 \cdot 15)$ & $-2 \cdot 7(3.9)^{\star \star}$ & $0 \cdot 59(0 \cdot 11)$ & $-0 \cdot 8(2 \cdot 0)$ & $0 \cdot 56(0 \cdot 12)$ & $-2 \cdot 1(3 \cdot 0)^{\star \star}$ & $0 \cdot 100$ \\
\hline Cortical thickness (mm) & $1 \cdot 3(0 \cdot 3)$ & $-0 \cdot 8(0 \cdot 7)^{* * *}$ & $1 \cdot 8(0 \cdot 3)$ & $-0 \cdot 7(0 \cdot 4)^{* * *}$ & $1 \cdot 8(0 \cdot 3)$ & $-0.9(0.5)^{\star * *}$ & $0 \cdot 465$ \\
\hline $\operatorname{SSI}\left(\mathrm{mm}^{3}\right)$ & $136 \cdot 5(47 \cdot 3)$ & $-0 \cdot 7(1 \cdot 2)^{\star}$ & $175 \cdot 0(39 \cdot 4)$ & $-1 \cdot 3(1 \cdot 2)^{\star * *}$ & $239 \cdot 1(64 \cdot 4)$ & $-0 \cdot 6(1 \cdot 3)$ & $0 \cdot 106$ \\
\hline SSI (height adjusted) & & $1 \cdot 0(1 \cdot 2)^{* * *}$ & & $0 \cdot 5(1 \cdot 2)$ & & $1 \cdot 2(1 \cdot 3)^{* * *}$ & $0 \cdot 105$ \\
\hline Muscle area $\left(\mathrm{mm}^{2}\right)$ & $1886 \cdot 2(438 \cdot 9)$ & $-0.9(1.2)^{\star \star}$ & $2240 \cdot 4(292 \cdot 1)$ & $-1 \cdot 3(1 \cdot 1)^{\star * *}$ & $2439 \cdot 2(277 \cdot 6)$ & $-1 \cdot 3(1 \cdot 0)^{* * *}$ & $0 \cdot 400$ \\
\hline Muscle area (height adjusted) & & $1 \cdot 5(2 \cdot 3)^{\star *}$ & & $0 \cdot 6(2 \cdot 4)$ & & $0 \cdot 4(2 \cdot 0)$ & $0 \cdot 257$ \\
\hline $\mathrm{BMC} / \mathrm{MA}$ & $2 \cdot 9(0 \cdot 4)$ & $-0 \cdot 5(1 \cdot 0)^{\star}$ & $3 \cdot 1(0 \cdot 4)$ & $-0 \cdot 3(1 \cdot 1)$ & $3 \cdot 4(0 \cdot 5)$ & $0 \cdot 2(1 \cdot 2)$ & $0 \cdot 175$ \\
\hline
\end{tabular}

Values are expressed as mean (SD). Age-related values are shown if not stated otherwise. Comparison to healthy population was tested by one-sample $t$-test, sign test was used instead, whenever normality was rejected by Shapiro-Wilk test: ${ }^{\star} P<0 \cdot 05,{ }^{* *} P<0 \cdot 01,{ }^{* * *} P<0 \cdot 001$. One-way ANova was used to compare subgroups, intergroup significances in $Z$-scores (if available) are expressed as $P$-values. SSI, strength-strain index. BMC/MA, bone mineral content/muscle area. 
Multivariate and univariate multiple regression analysis was used to assess the dependency of logarithmically transformed bone measures on the duration of growth hormone and oestrogen therapy after adjustment for age, age squared and height $Z$-score (Fig. 3). The same linear regression model was used for all bone measures except for cortical vBMD, where cortical thickness $Z$-score was also included. The residuals in the multiple regression models were tested for normality using Shapiro-Wilk test (normality was rejected only for diaphyseal total area, but the model without the outlier was very similar).
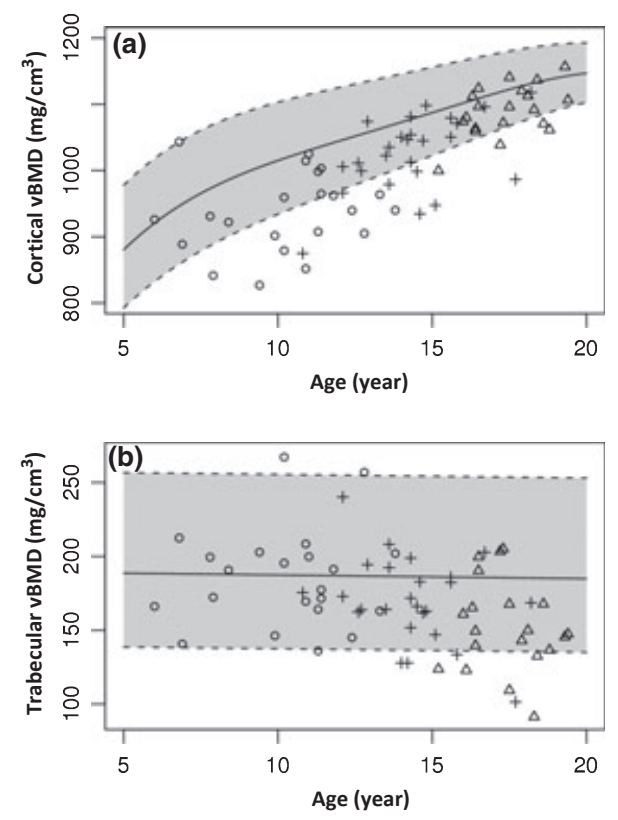

Fig. 1 Individual values for cortical (a) and trabecular (b) volumetric bone mineral density $v s$ age at the radius in Turner syndrome girls. Open circles represent prepubertal, daggers pubertal and triangles postpubertal girls. Nomogram represents mean $\pm 2 \mathrm{SD}$ of healthy population.

\section{Results}

\section{Differences between prepubertal, pubertal and postpubertal girls with TS}

Densitometric parameters expressed as mean values and mean ageand height-specific $Z$-scores for the prepubertal, pubertal and postpubertal groups are summarized in Table 2.

At the distal radius (4\% site), age-adjusted total area was normal in prepubertal and pubertal girls $(P=0.605$ and $P=0.761)$, but enlarged in the postpubertal group $(P=0 \cdot 003)$. A significant difference between the three groups was found for trabecular vBMD $(P=0.007)$, which was normal in prepubertal girls $(P=0.502)$, but decreased during and after puberty $(P=0.007$ and $P<0.001$; Fig. 1).

At the proximal radius (65\% site), age-adjusted total area was normal in the prepubertal and postpubertal groups $(P=0.384$ and $P=0.826)$, but decreased in pubertal girls $(P=0 \cdot 002$; Fig. 2$)$. In contrast, substantially higher values were gained when height-specific $Z$-scores were calculated, showing enlarged total area in prepubertal and postpubertal girls $(P=0.024$ and $P=0.022)$ and comparable total area in pubertal group $(P=0.695$; Table 2$)$. Similarly, the results for cortical area, SSI, muscle area and also BMC were substantially influenced by the selected method of comparison (age- or height-adjustment). For all these variables, considerably better results were observed after adjustment for body height (Table 2). Mean age-specific $Z$-scores for cortical vBMD and cortical thickness were low in all age groups $(P<0.001$ for all; Table 2 , Figs 1 and 2). Relative cortical area was decreased in prepubertal and postpubertal groups $(P=0.004$ and $P=0.006)$, but normal in pubertal girls ( $P=0 \cdot 052$; Table 2, Fig. 2).

\section{Predictors of bone parameters in TS}

The effect of GH and oestrogens on bone variables in TS was statistically significant (multivariate multiple regression model, Pillai-
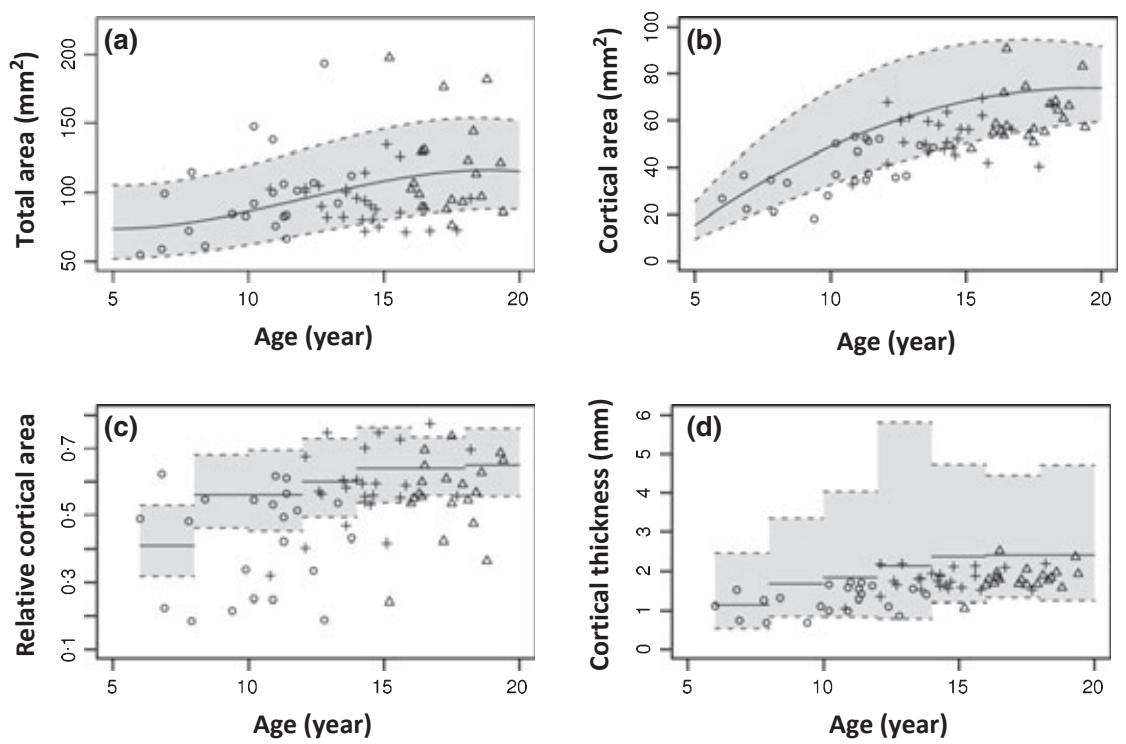

Fig. 2 Individual values for total area (a), cortical area (b), relative cortical area (c) and cortical thickness (d) $v s$ age at the proximal radius in Turner syndrome girls. Open circles represent prepubertal, daggers pubertal and triangles postpubertal girls. Nomogram represents mean $\pm 2 \mathrm{SD}$ of healthy population. 


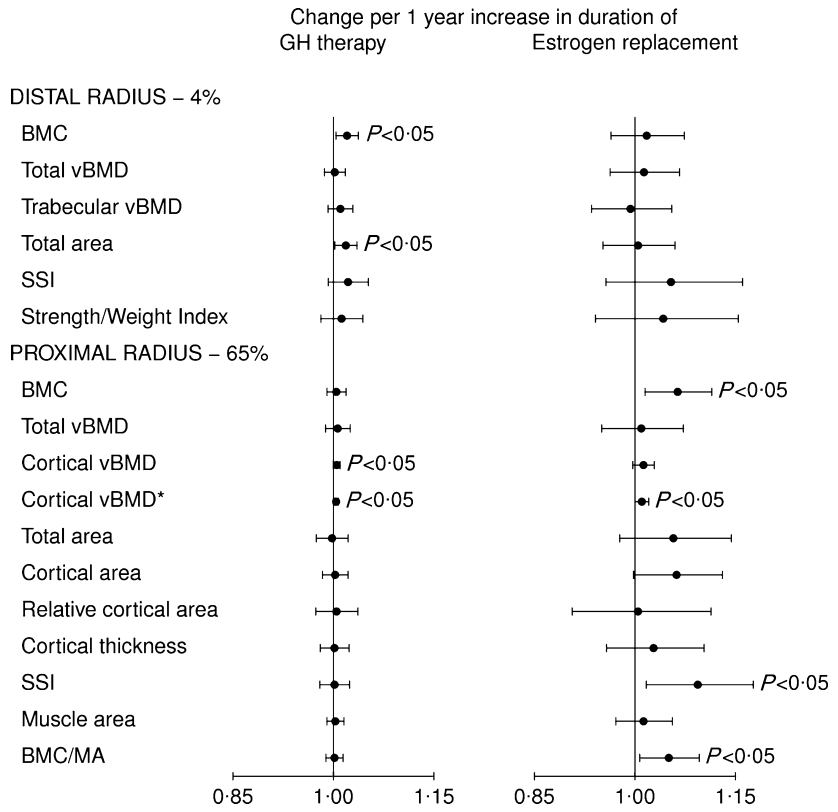

Fig. 3 Changes in bone parameters (dependent variables) predicted by 1 -year increment of growth hormone therapy and oestrogen replacement duration (expressed as exponentials of beta coefficients with 95\% CI). Multiple regression analysis with correction for age, age squared and height $Z$-score. For cortical volumetric bone mineral density, cortical thickness $Z$-score was also included in the model (indicated by asterisk). Values of bone parameters were logarithmically transformed.

Bartlett test, $P$-value $0 \cdot 0073)$. The size of the effect on each of the bone variables was assessed using univariate multiple regression models.

At the distal radius, an increase in duration of $\mathrm{GH}$ therapy by 1 year corresponded to $2 \cdot 0 \%$ (95\% CI $0 \cdot 38-3 \cdot 6 \%$ ) gain in BMC and to $1 \cdot 8 \%$ (95\% CI $0 \cdot 20-3 \cdot 4 \%)$ gain in total area (Fig. 3). We did not find any significant association between either growth hormone or oestrogens and trabecular vBMD.

At the proximal radius, an increase in duration of GH therapy by 1 year (Fig. 3) corresponded to $0.5 \%$ (95\% CI $0.01-0.98 \%$ ) increase in cortical vBMD. Because there was a significant correlation between cortical vBMD and cortical thickness in our patients $(r=0.86)$, a correlation caused by the partial volume effect, ${ }^{21}$ we added cortical thickness $Z$-score in the multiple regression model for cortical vBMD to account for possible bias. After this adjustment, an increment in duration of $\mathrm{GH}$ or oestrogen therapy by 1 year was associated with $0 \cdot 40 \%$ (95\% CI $0 \cdot 090-0 \cdot 70 \%$ ) and $1.0 \%(95 \%$ CI $0 \cdot 020-2 \cdot 0 \%)$ respective gain in cortical vBMD (Fig. 3).

A 1-year increase in duration of oestrogen therapy corresponded to increments in diaphyseal BMC of 6.2\% (95\% CI 1.5-10.9\%), in BMC/MA ratio of $4 \cdot 9 \%(95 \%$ CI $0 \cdot 70-9 \cdot 2 \%)$ and in diaphyseal SSI of $9 \cdot 0 \%$ (95\% CI $1 \cdot 7-16 \cdot 3 \%)$.

\section{History of fractures and bone parameters in TS}

A positive fracture history was reported in 14/67 (21\%) girls with TS. The total number of reported fractures was 26 (13 wrist fractures, 10 forearm fractures, 1 shank fracture, 1 finger fracture and 1 nontraumatic vertebral fracture). Three girls fractured twice, 1 girl fractured three times and two girls had experienced four lifetime fractures.

TS girls with positive history of fractures had significantly lower total $v B M D$ at the distal radius compared to nonfractured patients (Table 3). No significant changes were found between the two groups in any other of the bone parameters, GH or oestrogen treatment duration, or age at treatment start. Finally, we did not find any differences in the analysed bone and muscle parameters between the two groups to be influenced by the karyotype.

\section{Discussion}

In this study, we characterized bone geometry and volumetric BMD at the radius in prepubertal, pubertal and postpubertal girls with Turner syndrome using peripheral QCT. We found that (i) cortical area and cortical thickness at the diaphysis of the radius are low in all age groups, while total area is normal except for a

Table 3. Differences in clinical and bone characteristics between nonfractured and fractured girls with Turner syndrome

\begin{tabular}{|c|c|c|c|c|c|}
\hline & Value & $Z$-score & Value & $Z$-score & $\begin{array}{l}\text { Group difference } \\
(P \text {-value })\end{array}$ \\
\hline \multicolumn{6}{|l|}{ Anthropometry } \\
\hline Age (year) & $13 \cdot 9(3 \cdot 3)$ & & $14 \cdot 0(3 \cdot 7)$ & & $0 \cdot 901$ \\
\hline Height $(\mathrm{cm})$ & $146 \cdot 4(12 \cdot 4)$ & & $147 \cdot 0(16 \cdot 0)$ & & $0 \cdot 889$ \\
\hline Total vBMD $\left(\mathrm{mg} / \mathrm{cm}^{3}\right)$ & $279 \cdot 4(42 \cdot 5)$ & $-0 \cdot 9(1 \cdot 3)$ & $257 \cdot 5(43 \cdot 7)$ & $-1 \cdot 7(1 \cdot 1)$ & $0 \cdot 039$ \\
\hline Total area $\left(\mathrm{mm}^{2}\right)$ & $272 \cdot 0(63 \cdot 8)$ & $0 \cdot 0(1 \cdot 3)$ & $298 \cdot 9(83 \cdot 0)$ & $0.7(1 \cdot 1)$ & $0 \cdot 071$ \\
\hline Trabecular vBMD $\left(\mathrm{mg} / \mathrm{cm}^{3}\right)$ & $171 \cdot 6(33 \cdot 7)$ & $-0 \cdot 7(1 \cdot 3)$ & $163 \cdot 0(32 \cdot 9)$ & $-0 \cdot 9(1 \cdot 1)$ & $0 \cdot 434$ \\
\hline SSI $\left(\mathrm{mm}^{3}\right)$ & $203 \cdot 3(91 \cdot 4)$ & - & $191 \cdot 2(91 \cdot 6)$ & - & $0 \cdot 662$ \\
\hline Strength/weight index $\left(\mathrm{mm}^{3} / \mathrm{kg} / \mathrm{m}\right)$ & $20 \cdot 5(5 \cdot 9)$ & - & $20 \cdot 1(7 \cdot 6)$ & - & $0 \cdot 824$ \\
\hline
\end{tabular}

Values are expressed as mean (SD). Two-sample $t$-test was used to compare subgroups, intergroup significances in $Z$-scores (if available) are expressed as $P$-values. vBMD, volumetric bone mineral density; BMC, bone mineral content; SSI, strength-strain index. 
decrease in the pubertal group. However, after adjustment for body height, total area is generally enlarged (except in the pubertal group where it is normal), while cortical area is normal in all age groups; (ii) cortical vBMD is decreased in all age groups; (iii) trabecular vBMD is normal in prepubertal girls but deteriorates during and after puberty; (iv) the duration of GH and oestrogen therapy correlates positively with cortical vBMD; and (v) total vBMD at the metaphysis is significantly lower in patients with a positive fracture history.

\section{Bone geometry of the radius}

Bone geometry is strongly influenced by body height. Therefore, dimensional scaling is mandatory when assessing bone variables in children with short stature, such as patients with TS. We found that the radius is enlarged in prepubertal and postpubertal girls with TS at the diaphyseal cross-section after an adjustment for height. An enlargement of bone cross-section leading to greater resistance to bending and torsion has been described as a physiological adaptation of the bone to mechanical loading mediated by skeletal muscle contraction. $^{22,23}$ Therefore, an enlarged total area in subjects with a disrupted cortical bone could be interpreted as a result of an adjustment of bones to mechanical loading, aiming to decrease bone fragility. In accordance with this concept, we found a high height-adjusted proximal radius SSI in prepubertal and postpubertal groups. Different results seen in the pubertal group could be explained by the fact that we always compared girls of a different pubertal status, using either height- or age-specific $Z$-scores. Pubertal girls with TS are hyperestrinic compared to height-matched (i.e. prepubertal) healthy peers, but hypoestrinic compared to agematched healthy girls. Wang et al. ${ }^{24}$ found out recently that the serum estradiol level correlates negatively with endocortical circumference at the tibial shaft in healthy pubertal girls, but later on after menarche, a positive correlation was found with total bone area. Thus, lower oestrogen doses administered to our pubertal TS girls could have acted primarily on the endocortical bone surface, causing an increase in the cortical thickness and the relative cortical area, whereas higher doses given to postpubertal TS girls could have promoted periosteal expansion, causing enlargement of the bone.

\section{Cortical vBMD and cortical thickness}

The low cortical vBMD observed in our TS girls supports the hypothesis of a selective cortical bone deficit in TS, as previously postulated in the literature. ${ }^{9,25}$ Bakalov et al. ${ }^{25}$ found decreased aBMD at the distal third of radius (a site with prevalent cortical bone) using DXA in adult patients with TS and Holroyd et al. ${ }^{9}$ found decreased cortical vBMD at the radius using pQCT in postpubertal TS girls. However, the assessment of cortical vBMD values is biased by cortical thickness. This is because of a partial volume effect, ${ }^{21}$ which is bound to result in falsely low values especially in subjects with thin cortices, including girls with TS. The thinner the cortex, the higher the proportion of voxels comprising soft tissues at the cortical bone margin (periosteum and endosteum). Thus, it seems that the low cortical vBMD readings in TS (described here and in literature) correspond at least partly to an effect of thin cortices. Hence, in an attempt to adjust for the partial volume effect, a correction formula was used devised by Rittweger et al. ${ }^{26}$ When this correction algorithm was applied, cortical vBMD was found to be elevated above normal (mean $Z$-scores $1 \cdot 1,0 \cdot 7$ and $1 \cdot 4, P<0 \cdot 01$ for all). A validation of the algorithm using synthetic specimens ${ }^{26}$ has shown that it slightly under-corrects the cortical vBMD, rather than over-correcting it. Therefore, it is unlikely that the application of this correction algorithm is responsible for the elevated cortical vBMD values found in TS children. On the other hand, one also has to consider beam hardening, which is bound to show a lower cortical density in larger bones, and which could thus explain the effect. In conclusion, the question of whether cortical vBMD is reduced in TS children remains yet open. It is, however, important to realize that such a difference would be relatively small $(78 \cdot 13,52.01$ and $29.08 \mathrm{mg} / \mathrm{cm}^{3}$ for prepubertal, pubertal and postpubertal group, respectively) and that the main effects of TS on bone are linked to bone geometry, and not tissue density.

\section{Trabecular vBMD}

Oestrogens have strong effects upon the trabecular network. Our finding of decreased trabecular vBMD during and after puberty could therefore be expected in hypogonadal TS girls. Our observation generally agrees with studies showing normal size-adjusted lumbar spine areal BMD before puberty but a lack of adequate pubertal bone mass acquisition in TS girls. ${ }^{27,28}$ Similar results were observed in hypogonadal patients assessed by QCT. ${ }^{7}$ However, the only two previously published studies performed on postpubertal TS girls using pQCT showed normal trabecular vBMD at the radius. ${ }^{8,9}$ We have no clear explanation for this contradiction. We may only speculate about the type and/or dosage of oestrogens used that was different in study by Bechtold et al. (estradiol valerate $2 \mathrm{mg} /$ day) and our study (17- $\beta$-estradiol $1.2 \mathrm{mg} /$ day), and a different age at densitometry $(19 \cdot 5 \pm 2 \cdot 3$ vs $17 \cdot 2 \pm 1 \cdot 3$ years in our postpubertal girls), but further research is needed to provide more insight into this issue.

\section{GH therapy and bone}

The impact of GH on bone density is still controversial. There is no doubt that GH and IGF-1 have an anabolic effect on bone and muscle, stimulating bone growth in length (by stimulation of the growth plate) and width (by periosteal expansion mediated mostly through muscles). Nevertheless, data on the skeletal effects of GH in TS and other non-GHD subjects are still limited. Whereas GH therapy was reported to lead to a gain in mid-phalangeal BMD in pubertal TS patients in a single radiographic absorptiometry study, ${ }^{29}$ the DXA studies described an increment in bone area but not the aBMD at the radius, ${ }^{30}$ and an increase in muscle mass but no change in the total body $\mathrm{aBMD}^{31}$ in patients with TS. Our finding that the duration of the GH therapy is positively correlated with cortical vBMD is consistent with studies published on patients with acromegaly - these described increased cortical but not trabecular BMD at different sites, including the radius. ${ }^{32,33}$ 
In addition, a single placebo-controlled study showed a dosedependent effect of GH to increase femoral neck and total body BMC in osteoporotic non-GHD elderly women. ${ }^{34}$ Moreover, in experiments on rodents, $\mathrm{GH}$ administration to non-GHD rats lead to increased cortical bone mass and bone strength. ${ }^{35}$ However, further longitudinal studies are needed to clarify this point.

\section{Oestrogens and the bone}

We found that the duration of oestrogen replacement was positively correlated with cortical vBMD, BMC, BMC/MA and SSI at the radial diaphysis. This is in accordance with the results of a single placebo-controlled study in TS describing an association between oestrogen replacement and gain in mid-phalangeal BMD, i.e. a cortical bone site. ${ }^{36}$ Our findings support the mechanostat theory denoting oestrogens as modulators of bone resorption threshold at the endocortical site. The positive effect of oestrogens on bone reported in the present study is in accordance with the finding by Landin-Wilhelmsen et al. ${ }^{1}$ who described a 19-fold increase in the fracture risk in untreated women with TS aged $>45$ compared to the general population.

\section{Bone strength and fractures in TS}

An increased rate of fractures has been reported in patients with TS. ${ }^{1,2}$ Interestingly, the fracture risk was significantly different from the general population only at the forearm (relative risk of 1.9). ${ }^{2}$ This finding makes the pQCT a promising method for bone analysis in TS, because the measurement is performed directly at the site of the increased fracture risk. In this study, we showed for the first time that girls with TS who underwent at least one fracture in their life have a lower total vBMD at the distal radius when compared to the nonfractured subjects. The total vBMD at this site represents the combined density of the cortical bone envelope and the trabecular bone inside. As there was no difference in the trabecular vBMD between the two groups, a more pronounced cortical bone deficit in fractured girls could be responsible for this finding. However, because of very thin cortices at the metaphysis, we could not further verify this hypothesis by assessing cortical bone at the distal site by $\mathrm{pQCT}$.

The limitation of this study lies in its cross-sectional design. Prospective studies are needed to find out whether correlations of GH and oestrogens to the densitometric variables observed in this study reflect a truly causal mechanism, or whether our observations are because of an action of a yet unknown confounder influencing bone strength in TS girls.

In conclusion, our study describes differences in bone geometry and volumetric BMD at the radius in a considerable number of girls with TS of different pubertal stages. The altered bone geometry is probably the result of bone adaptation to mechanical loading in the presence of a cortical bone deficit, and oestrogens may play a role in the changes in bone geometry according to the pubertal stage. Longitudinal data are needed to elucidate the role of the hormonal therapy on bone and to find the best predictor for fractures in patients with TS.

\section{Declaration of interest}

No conflicts declared.

\section{Funding}

This work was supported by Charles University (GAUK 47609), Czech Ministry of Health (VZ MZ 64203) and Czech Ministry of Education (MSMT 21620819).

\section{Disclosure}

The authors have nothing to declare.

\section{References}

1 Landin-Wilhelmsen, K., Bryman, I., Windh, M. et al. (1999) Osteoporosis and fractures in Turner syndrome-importance of growth promoting and oestrogen therapy. Clinical Endocrinology, 51, 497502.

2 Gravholt, C.H., Vestergaard, P., Hermann, A.P. et al. (2003) Increased fracture rates in Turner's syndrome: a nationwide questionnaire survey. Clinical Endocrinology, 59, 89-96.

3 Gravholt, C.H., Lauridsen, A.L., Brixen, K. et al. (2002) Marked disproportionality in bone size and mineral, and distinct abnormalities in bone markers and calcitropic hormones in adult turner syndrome: a cross-sectional study. Journal of Clinical Endocrinology \& Metabolism, 87, 2798-2808.

4 Bakalov, V.K., Chen, M.L., Baron, J. et al. (2003) Bone mineral density and fractures in Turner syndrome. The American Journal of Medicine, 115, 259-264.

5 Lage, A.Z., Brandao, C.A., Mendes, J.R. et al. (2005) High degree of discordance between three-dimensional and two-dimensional lumbar spine bone mineral density in Turner's syndrome. Journal of Clinical Densitometry, 8, 461-466.

6 Carter, D.R., Bouxsein, M.L. \& Marcus, R. (1992) New approaches for interpreting projected bone densitometry data. Journal of Bone and Mineral Research, 7, 137-145.

7 Nanao, K., Tsuchiya, Y., Kotoh, S. et al. (2002) Low vertebral cancellous bone density in peripubertal girls with Turner's syndrome and boys with hypogonadism. Journal of Pediatric Endocrinology and Metabolism, 15, 1537-1542.

8 Bechtold, S., Rauch, F., Noelle, V. et al. (2001) Musculoskeletal analyses of the forearm in young women with Turner syndrome: a study using peripheral quantitative computed tomography. Journal of Clinical Endocrinology \& Metabolism, 86, 5819-5823.

9 Holroyd, C.R., Davies, J.H., Taylor, P. et al. (2010) Reduced cortical bone density with normal trabecular bone density in girls with Turner syndrome. Osteoporosis International, 21, 2093-2099.

10 Saenger, P., Wikland, K.A., Conway, G.S. et al. (2001) Recommendations for the diagnosis and management of Turner syndrome. Journal of Clinical Endocrinology \& Metabolism, 86, 3061-3069.

11 van Pareren, Y.K., de Muinck Keizer-Schrama, S.M., Stijnen, T. et al. (2003) Final height in girls with turner syndrome after longterm growth hormone treatment in three dosages and low dose estrogens. Journal of Clinical Endocrinology \& Metabolism, 88, $1119-1125$.

12 Rosenfield, R.L., Devine, N., Hunold, J.J. et al. (2005) Salutary effects of combining early very low-dose systemic estradiol with 
growth hormone therapy in girls with Turner syndrome. Journal of Clinical Endocrinology \& Metabolism, 90, 6424-6430.

13 Kobzova, J., Vignerova, J., Blaha, P. et al. (2004) The 6th nationwide anthropological survey of children and adolescents in the Czech Republic in 2001. Central European Journal of Public Health, 12, 126-130.

14 Rauch, F., Neu, C., Manz, F. et al. (2001) The development of metaphyseal cortex-implications for distal radius fractures during growth. Journal of Bone and Mineral Research, 16, 1547-1555.

15 Rauch, F. \& Schoenau, E. (2005) Peripheral quantitative computed tomography of the distal radius in young subjects - new reference data and interpretation of results. Journal of Musculoskeletal and Neuronal Interactions, 5, 119-126.

16 Rauch, F. \& Schoenau, E. (2008) Peripheral quantitative computed tomography of the proximal radius in young subjects-new reference data and interpretation of results. Journal of Musculoskeletal and Neuronal Interactions, 8, 217-226.

17 Neu, C.M., Rauch, F., Manz, F. et al. (2001) Modeling of crosssectional bone size, mass and geometry at the proximal radius: a study of normal bone development using peripheral quantitative computed tomography. Osteoporosis International, 12, 538547.

18 Cole, T.J. (1990) The LMS method for constructing normalized growth standards. European Journal of Clinical Nutrition, 44, 4560.

19 Gordon, C.M., Bachrach, L.K., Carpenter, T.O. et al. (2008) Dual energy X-ray absorptiometry interpretation and reporting in children and adolescents: the 2007 ISCD Pediatric Official Positions. Journal of Clinical Densitometry, 11, 43-58.

20 Team, R.D.C. (2009) R: A Language and Environment for Statistical Computing. R Foundation for Statistical Computing, Vienna, Austria.

21 Schoenau, E., Neu, C.M., Rauch, F. et al. (2002) Gender-specific pubertal changes in volumetric cortical bone mineral density at the proximal radius. Bone, 31, 110-113.

22 Frost, H.M. (1998) From Wolff's law to the mechanostat: a new "face" of physiology. Journal of Orthopaedic Science, 3, 282-286.

23 Seeman, E. (2008) Bone quality: the material and structural basis of bone strength. Journal of Bone and Mineral Metabolism, 26, 1-8.

24 Wang, Q., Alen, M., Nicholson, P.H. et al. (2006) Differential effects of sex hormones on peri- and endocortical bone surfaces in pubertal girls. Journal of Clinical Endocrinology \& Metabolism, 91, 277-282.
25 Bakalov, V.K., Axelrod, L., Baron, J. et al. (2003) Selective reduction in cortical bone mineral density in turner syndrome independent of ovarian hormone deficiency. Journal of Clinical Endocrinology \& Metabolism, 88, 5717-5722.

26 Rittweger, J., Michaelis, I., Giehl, M. et al. (2004) Adjusting for the partial volume effect in cortical bone analyses of pQCT images. Journal of Musculoskeletal and Neuronal Interactions, 4, 436-441.

27 Ross, J.L., Long, L.M., Feuillan, P. et al. (1991) Normal bone density of the wrist and spine and increased wrist fractures in girls with Turner's syndrome. Journal of Clinical Endocrinology \& Metabolism, 73, 355-359.

28 Shaw, N.J., Rehan, V.K., Husain, S. et al. (1997) Bone mineral density in Turner's syndrome-a longitudinal study. Clinical Endocrinology, 47, 367-370.

29 Sass, T.C., De Muinck Keizer-Schrama, S.M., Stijnen, T. et al. (2000) A longitudinal study on bone mineral density until adulthood in girls with Turner's syndrome participating in a growth hormone injection frequency-response trial. Clinical Endocrinology, 52, 531-536.

30 Bakalov, V.K., Van, P.L., Baron, J. et al. (2004) Growth hormone therapy and bone mineral density in Turner syndrome. Journal of Clinical Endocrinology \& Metabolism, 89, 4886-4889.

31 Ari, M., Bakalov, V.K., Hill, S. et al. (2006) The effects of growth hormone treatment on bone mineral density and body composition in girls with turner syndrome. Journal of Clinical Endocrinology \& Metabolism, 91, 4302-4305.

32 Andreassen, T.T. \& Oxlund, H. (2001) The effects of growth hormone on cortical and cancellous bone. Journal of Musculoskeletal and Neuronal Interactions, 2, 49-58.

33 Ueland, T., Ebbesen, E.N., Thomsen, J.S. et al. (2002) Decreased trabecular bone biomechanical competence, apparent density, IGFII and IGFBP-5 content in acromegaly. European Journal of Clinical Investigation, 32, 122-128.

34 Landin-Wilhelmsen, K., Nilsson, A., Bosaeus, I. et al. (2003) Growth hormone increases bone mineral content in postmenopausal osteoporosis: a randomized placebo-controlled trial. Journal of Bone and Mineral Research, 18, 393-405.

35 Kalu, D.N., Banu, J. \& Wang, L. (2000) How cancellous and cortical bones adapt to loading and growth hormone. Journal of Musculoskeletal and Neuronal Interactions, 1, 19-23.

36 van Teunenbroek, A., Mulder, P., de Muinck Keizer-Schrama, S. et al. (1995) Radiographic absorptiometry of the phalanges in healthy children and in girls with Turner syndrome. Bone, 17, 7178 . 